\title{
Ovine and murine T cell epitopes from the non-structural protein 1 (NS1) of bluetongue virus serotype 8 (BTV-8) are shared among viral serotypes
}

\author{
José M Rojas ${ }^{1,2}$, Lourdes Peña ${ }^{1}$, Verónica Martín ${ }^{1}$ and Noemí Sevilla ${ }^{1 *}$
}

\begin{abstract}
Bluetongue virus (BTV) is a non-enveloped dsRNA virus that causes a haemorrhagic disease mainly in sheep. It is an economically important Orbivirus of the Reoviridae family. In order to estimate the importance of T cell responses during BTV infection, it is essential to identify the epitopes targeted by the immune system. In the present work, we selected potential T cell epitopes (3 MHC-class II-binding and 8 MHC-class I binding peptides) for the C57BL/6 mouse strain from the BTV-8 non-structural protein NS1, using $\mathrm{H}_{2} \mathrm{~b}$-binding predictive algorithms. Peptide binding assays confirmed all MHC-class I predicted peptides bound MHC-class I molecules. The immunogenicity of these 11 predicted peptides was then determined using splenocytes from BTV-8-inoculated C57BL/6 mice. Four MHC-class I binding peptides elicited specific IFN- $\gamma$ production and generated cytotoxic T lymphocytes (CTL) in BTV-8 infected mice. CTL specific for 2 of these peptides were also able to recognise target cells infected with different BTV serotypes. Similarly, using a combination of IFN- $\gamma$ ELISPOT, intracellular cytokine staining and proliferation assays, two MHC-class II peptides were identified as CD4 ${ }^{+}$T cell epitopes in BTV-8 infected mice. Importantly, two peptides were also consistently immunogenic in sheep infected with BTV-8 using IFN- $\gamma$ ELISPOT assays. Both of these peptides stimulated $\mathrm{CD}^{+} \mathrm{T}$ cells that cross-reacted with other BTV serotypes. The characterisation of these T cell epitopes can help develop vaccines protecting against a broad spectrum of BTV serotypes and differentiate infected from vaccinated animals.
\end{abstract}

\section{Introduction}

Bluetongue virus (BTV) is the prototype member of the Orbivirus genus of the Reoviridae family, transmitted to the vertebrate host by biting midges [1]. The genome consists of ten double-stranded RNA segments, encoding 7 structural- and 4 non-structural- proteins [2,3]. The outer capsid layer includes VP2 and VP5 [4,5] responsible for eliciting serotype-specific neutralising antibodies [6,7]. The non-structural (NS) proteins are involved in the control of BTV replication, maturation and export from the cell $[8,9]$.

A long-lasting immunity is developed in animals that recover from bluetongue where both neutralising antibodies

\footnotetext{
* Correspondence: sevilla@inia.es

${ }^{1}$ Centro de Investigación en Sanidad Animal (CISA-INIA), Instituto Nacional de Investigación Agraria y Alimentaria, Valdeolmos, Madrid, Spain

Full list of author information is available at the end of the article
}

[10] and cytotoxic T lymphocytes (CTL) [11,12] are involved in this protective immunity. However, the variability of the outer capsid of this virus represents one of the major challenges for the development of a vaccine capable of protecting animals against multiple serotypes. On the other hand, cellular immunity plays a key role in BTV immunity as adoptive transfer of lymphocytes could partially protect monozygotic sheep from subsequent BTV challenge [13] and protection can exist in the absence of neutralising antibodies [14,15]. Importantly, the determinants for cellular immunity are more likely to be shared among serotypes. Indeed, BTV vaccination and infection in sheep induces CTLs cross-reactive to multiple serotypes [11,16-18]. Based on this observation, vaccination designed to elicit $\mathrm{T}$ cell responses can potentially protect animals against several BTV serotypes.

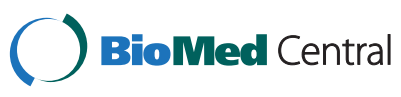

(c) 2014 Rojas et al.; licensee BioMed Central Ltd. This is an Open Access article distributed under the terms of the Creative Commons Attribution License (http://creativecommons.org/licenses/by/2.0), which permits unrestricted use, distribution, and reproduction in any medium, provided the original work is properly credited. The Creative Commons Public Domain Dedication waiver (http://creativecommons.org/publicdomain/zero/1.0/) applies to the data made available in this article, unless otherwise stated. 
Analysis of CTL responses to BTV in experimentally infected sheep showed that virtually all animals recognise epitopes within the non-structural protein 1 (NS1) [11]. Thus, we have investigated $\mathrm{T}$ cell epitopes from the NS1 protein capable of cross-reacting with multiple BTV serotypes both in sheep and mouse, as murine models of BTV infection represent a valuable tool for designing novel vaccination strategies $[19,20]$. In the present report we identify novel $\mathrm{CD} 4^{+}$and $\mathrm{CD}^{+}{ }^{+} \mathrm{T}$ cell epitopes in mouse model from the NS1 protein of BTV-8, as well as two immunoreactive CD4 epitopes in BTV-8 infected sheep capable of cross-reacting with other serotypes. This work underlines the potential of stimulating anti-BTV $\mathrm{T}$ cells in order to develop more effective vaccinations.

\section{Material and methods}

\section{Cell lines, virus stock preparation and inactivation}

BTV stocks and virus titres were prepared as described previously [21]. Briefly, Baby Hamster Kidney (BHK) cells were infected with BTV at multiplicity of infection of 1 and culture supernatants were collected after $48 \mathrm{~h}$. After 3 cycles of freeze/thaw and a 2-min sonication step, the supernatants were clarified by centrifugation and stored at $-80{ }^{\circ} \mathrm{C}$ until use. Virus titres were determined using a standard plaque titration assay using the Vero cell line. Inactivated virus (BEI-BTV) were obtained by incubating viral stocks $\left(1 \times 10^{6}\right.$ plaque forming unit $\left.(\mathrm{pfu}) / \mathrm{mL}\right)$ for $48 \mathrm{~h}$ at $37^{\circ} \mathrm{C}$ with $3 \mathrm{mM}$ of freshly prepared binary ethyleneimine (BEI) and neutralised with $0.02 \mathrm{M}$ sodium thiosulphate at the end of the incubation time.

\section{Infections and animals}

Female (7-12 week-old) C57BL/6 mice (Harlan Interfauna Ibérica, Barcelona, Spain) were inoculated subcutaneously with 100 pfu of BTV-8 (Belgium/06) three times at 10 days intervals and sacrificed three days after the last inoculation. Three month-old female sheep (Mallorquina breed) $(n=8)$ were inoculated three times at 28-day intervals with $1 \times 10^{5}$ pfu BTV-8. Venous blood was collected 14 days after the last inoculation and peripheral blood leukocytes (PBL) were prepared as described below. All the procedures herein described were carried out under European Community guidelines and approved by the local ethical review committee.

\section{Peptides and peptide binding assays}

Peptide binding assays to $\mathrm{D}^{\mathrm{b}}$ and $\mathrm{K}^{\mathrm{b}}$ molecules were performed as previously described [21]. Putative binding peptides for $\mathrm{D}^{\mathrm{b}} / \mathrm{K}^{\mathrm{b}} / \mathrm{I}-\mathrm{A}^{\mathrm{b}}$ molecules from the NS1 protein of BTV-8 were selected using a combination of predictive algorithms available on the web [22-25] (Table 1). Peptides were purchased from Altabiosciences (Birmingham, UK) or Thermo Fisher Scientific (Ulm, Germany). The gp(33-41) peptide (KAVYNFATC) from lymphocytic choriomeningitis virus (LCMV) known to bind $\mathrm{D}^{\mathrm{b}}$ and $\mathrm{K}^{\mathrm{b}}$ molecules was used as irrelevant peptide where mentioned. Assays were performed at least 3 times and binding affinity was ranked according to peptide gp(33-41). All peptides were dissolved in DMSO and controls with equivalent amounts of DMSO were included in all experiments.

\section{Splenocytes and lymph node cells preparation}

Spleen and mesenteric lymph nodes were collected from inoculated mice three days after the last inoculation. Single cell suspensions were prepared by mechanical disruption of the organs through a cell strainer. After lysing the erythrocytes, splenocytes or lymph node cells from each mouse were tested against the appropriate stimuli individually at least in triplicate in $\mathrm{T}$ cell medium (RPMI supplemented with 10\%FCS (Lonza Biowhittaker, NJ, USA), 4 mM L-glutamine, $10 \mathrm{mM}$ HEPES, 1\% 100X non-essential aminoacids, $1 \mathrm{mM}$ sodium pyruvate, $100 \mathrm{U} / \mathrm{mL}$ penicillin $/ 100 \mu \mathrm{g} /$ $\mathrm{mL}$ streptomycin and 50nM $\beta$-mercaptoethanol (all from Gibco, Invitrogen)).

\section{PBL preparation and in vitro stimulation}

PBL were prepared by standard centrifugation method. Briefly, venous blood collected in EDTA $(6 \mathrm{mM}$ final concentration) was diluted 1:1 in PBS $+0.03 \%(w / v)$ EDTA (pH 7.4) and overlayed over a Ficoll cushion (GE Healthcare Europe $\mathrm{GmbH}$, Barcelona, Spain). Blood was centrifuged at $800 \times g$ for $30 \mathrm{~min}$ at room temperature without brake, and the PBL present at the interface were transferred to a fresh tube and washed with PBS $+0.03 \%(w / v)$ EDTA. Contaminant erythrocytes were lysed and after two further washes, cells were cryopreserved in 90\% FCS + 10\% DMSO until use. Sheep PBL were thawed by slowly diluting the cryovial content into PBL medium (RPMI $+17 \%$ AIM-V medium $+5 \% \quad$ FCS $+4 \quad \mathrm{mM} \quad$ L-Glutamine $+10 \quad \mathrm{mM}$ HEPES + 1\% 100X non-essential amino-acids + $1 \mathrm{mM}$ sodium pyruvate $+100 \mathrm{U} / \mathrm{mL}$ penicillin $/ 100 \mu \mathrm{g} / \mathrm{mL}$ streptomycin $+50 \quad \mathrm{nM} \quad \beta$-mercaptoethanol (all from Gibco, Invitrogen, CA, USA)). Sheep PBL were washed three times and rested for $1-2 \mathrm{~h}$ at room temperature in PBL medium before use. In some experiments, $5 \times 10^{6}$ sheep PBL per well were restimulated with $10 \mu \mathrm{g} / \mathrm{mL}$ of NS1 peptide in 24 well plates for 7 days prior to flow cytometry analysis for intracellular IFN- $\gamma$.

\section{ELISPOT assays}

Murine IFN- $\gamma$ ELISPOT assays were performed according to the manufacturer protocol (Diaclone, France). Briefly, $2 \times 10^{5}$ splenocytes per well were plated in the presence of $10 \mu \mathrm{g} / \mathrm{mL}$ peptide (final concentration) or chemicallyinactivated BTV (BEI-BTV). Ovine IFN- $\gamma$ ELISPOT assays were performed using MSIPS4510 plate (Millipore). Membranes were incubated at $4{ }^{\circ} \mathrm{C}$ with $5 \mu \mathrm{g} / \mathrm{mL}$ anti-ovine 
Table 1 Prediction of $\mathrm{H}-2^{b}$ binding peptides from NS1 and binding assays

\begin{tabular}{|c|c|c|c|c|c|c|c|}
\hline \multirow[b]{2}{*}{ Position } & \multirow[b]{2}{*}{ Name } & \multirow[b]{2}{*}{ Sequence } & \multirow[b]{2}{*}{ Predicted allele binding } & \multicolumn{3}{|c|}{ Predictive algorithm scores } & \multirow[b]{2}{*}{$\begin{array}{l}\text { Binding assay* } \\
\left(D^{b} / K^{b}\right)\end{array}$} \\
\hline & & & & $\begin{array}{l}\text { SYFPEITHI score } \\
\left(D^{\mathrm{b}} / K^{\mathrm{b}}\right)\end{array}$ & $\begin{array}{l}\text { NetMHC predicted affinity } \\
n M\left(D^{b} / K^{b}\right)\end{array}$ & $\begin{array}{l}\text { BIMAS proPred-I score } \\
\left(D^{\mathrm{b}} / \mathrm{K}^{\mathrm{b}}\right)\end{array}$ & \\
\hline 14 & NS1(14) & YANATRTFL & $D^{b}$ & 16 & 341 & 17.892 & + \\
\hline 125 & NS1(125) & SALVNSERV & $D^{b}$ & 28 & 10 & 138.526 & +++ \\
\hline 152 & NS1(152) & GQIVNPTFI & $D^{b}$ & 28 & 5 & 1502.928 & +++ \\
\hline 222 & NS1(222) & IQLINFLRM & $D^{b} / K^{b}$ & $22 / 17$ & $239 / 201$ & $226.359 / 11.000$ & $++/++$ \\
\hline 403 & NS1(403) & NCYTGAEAL & $D^{b} / K^{b}$ & $14 / 11$ & $21953 / 18590$ & $3.982 / 6.000$ & $+/-$ \\
\hline 141 & NS1(141) & AMPYIYVPI & $K^{b}$ & 22 & 137 & 19.800 & + \\
\hline 166 & NS1 (166) Cl I & IAYYFYNPD & $k^{b}$ & 19 & 30 & 1.320 & +++ \\
\hline 235 & NS1(235) & KHFNRYASM & $K^{b}$ & 17 & 22 & 40.000 & +++ \\
\hline 166 & NS1(166) Cl II & IAYYFYNPDAADDWI & $1-A^{b}$ & NA & 194.8 & NA & NA \\
\hline 402 & NS1(402) & TNCYTGAEALITTAI & $1-A^{b}$ & NA & 87.3 & NA & NA \\
\hline 522 & NS1(522) & KVHFAGFAAPACESG & $1-A^{b}$ & NA & 59.1 & NA & NA \\
\hline
\end{tabular}

NA: Not available.

*Peptides were ranked relative to the binding of the control peptide gp33-41 from LCMV to Db and Kb molecules on RMA-s cells (fluorescence ratio between NS1 peptide and gp33-41 peptide) (Rojas et al. [21]). +++ : strong binder where ratio $>0.9 ;++$ : moderate binder where ratio $>0.7$ and $<0.9 ;+$ : weak binder where ratio $>0.5$ and $<0.7$; and -: no binder where ratio $<0.5$. 
IFN- $\gamma$ antibody (MT17.1, Mabtech, Sweden). Sheep PBL were plated at a density of $2-3 \times 10^{5}$ cells per well and incubated with peptide $(10 \mu \mathrm{g} / \mathrm{mL})$, BEI-BTV, PBL medium as negative control or concanavalin- $\mathrm{A}(0.5 \mu \mathrm{g} / \mathrm{mL})$ as positive control. Membranes were incubated with biotinlabelled anti-ovine IFN- $\gamma$ antibody (MT307-biotin, Mabtech, Sweden) and developed with streptavidin conjugated to alkaline phosphatase (ExtrAvidin-AP, Sigma, USA). Membranes were revealed using SigmaFAST BCIP/NBT (Sigma).

\section{Proliferation assays and intracellular cytokine staining}

Splenocytes or sheep PBL $\left(2-3 \times 10^{5}\right.$ per well) were cultured in the presence of BEI-BTV or NS1 peptides $(10 \mu \mathrm{g} / \mathrm{mL})$. For proliferation assay, cells were cultured for $72 \mathrm{~h}$ before ${ }^{3} \mathrm{H}$-Thymidne was added to each well and incubated overnight. Data are presented as stimulation index (ratio of incorporated ${ }^{3} \mathrm{H}$-thymidine in test to control cultures) or as average cpm. For intracellular cytokine staining, splenocytes were stained with anti-mouse CD4-FITC and anti-mouse $\mathrm{CD} 8 \alpha-\mathrm{PcP}$ antibodies (both from BD Pharmingen, CA, USA) whereas sheep PBL were stained with antiovine CD4-FITC and anti-ovine CD8-PE antibodies (both from Serotec). After permeabilisation, splenocytes were stained with anti-mouse IFN- $\gamma$-PE and anti-mouse TNF- $\alpha$ APC (both from BD pharmingen), whereas sheep PBL were stained with anti-ovine IFN- $\gamma$-A647 (Serotec, UK).

\section{Cytotoxicity assays}

CTL assay was quantitated by a standard ${ }^{51} \mathrm{Cr}$-release assay $[21,26]$. Target cells (T) (RMA-S or MC57 cells) cells were pulsed for $1 \mathrm{~h}$ in serum-free medium at $37{ }^{\circ} \mathrm{C}, 5 \% \mathrm{CO}_{2}$ with $10 \mu \mathrm{g} / \mathrm{mL}$ of peptide (NS1 or irrelevant gp33-41 peptide), BEI-BTV (equivalent to $5 \times 10_{5} \mathrm{PFU} / \mathrm{mL}$ prior to inactivation) or BHK-mock lysate as negative control. Target cells (T) were labelled with $50 \mu \mathrm{Ci}$ of $\mathrm{Na}_{2}^{51} \mathrm{CrO}_{4}$ (Hartmann Analytic, Germany). Effector (E) (splenocytes) and target cells were cultured in triplicates at different ratios Culture supernatants were counted using a 1450 MicroBeta Trilux counter (Perkin-Elmer, Ohio, USA). The specific percentage lysis was calculated using the following formulae:

Percentage cytotoxicty $=\frac{(\text { Experimental release-Spontaneous release })}{(\text { Maximum release-Spontaneous release })}$

\section{Statistical analysis}

Unpaired two-tailed Student's $t$-tests were used to observe difference within the same animal, whereas nonparametric two-tailed Mann Whitney rank $U$ tests were used to compare group of values for several animals. Data handling analyses was performed using Prism 5.0 (GraphPad Software Inc. San Diego, CA, USA).

\section{Results}

Infection with BTV-8 induces T cell responses to other BTV serotypes in mice and sheep

Splenocytes from BTV-8 inoculated mice were cultured in the presence of inactivated virus. Proliferation (Figure 1A) and IFN- $\gamma$ (Figure 1B) were not only detected to inactivated BTV- 8 but also to inactivated BTV- 4 in all 5 mice tested
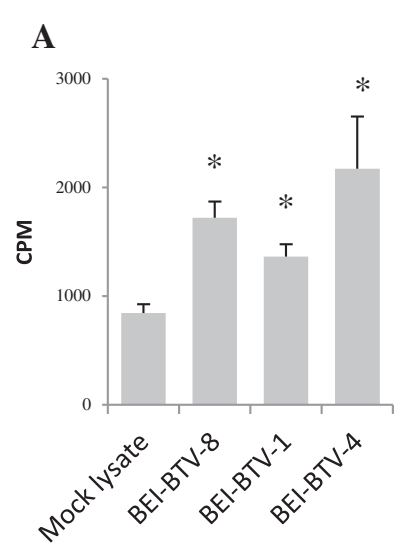

B

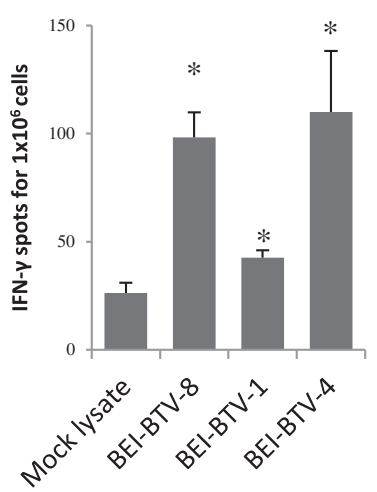

C

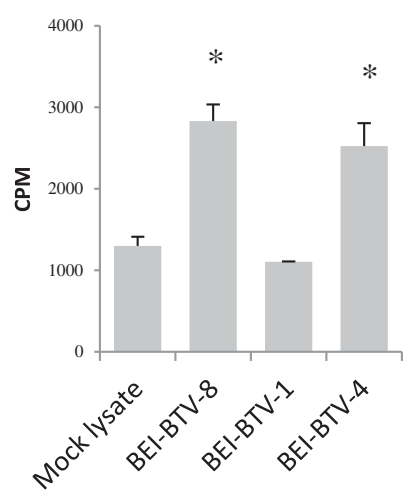

D

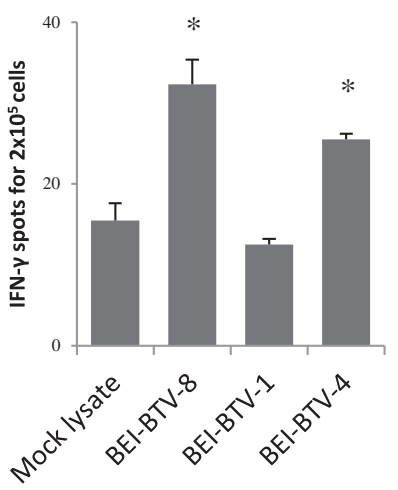

Figure 1 T cells from BTV-8 inoculated animals recognise antigenic determinants shared by BTV serotypes. C57BL/6 mice inoculated were sacrificed and splenocytes were cultured in the presence of inactivated BTV from different serotypes. (A) Proliferative responses to BTV were detected not only to the serotype used for vaccination (BTV-8) but also to serotype 1 and 4. (B) Similarly, splenocytes produced IFN- $\gamma$ specifically when in presence of BTV serotype 1, 4 and 8. Data presented are representative of 5 mice inoculated with BTV-8. (C) PBLs from BTV-8 infected sheep were cultured for 5 days in the presence of inactivated BTV from different serotypes and tritiated-thymidine was added in the last $16 \mathrm{~h}$ of culture. Proliferative response to BTV-4 and BTV-8 but not BTV-1 was detected in the cultures. Data presented are representative of 6 sheep. (D) PBLs from BTV-8 infected sheep were cultured with inactivated BTV from different serotypes for $48 \mathrm{~h}$ and IFN- $\gamma$ was measured by ELISPOT. IFN- $\gamma$ was produced to BTV-8 and BTV-4 but not BTV-1. Data presented are representative of 3 sheep. Proliferation is presented as the average cpm of ${ }^{3} \mathrm{H}$-thymidine incorporated in triplicate cultures and IFN-y ELISPOT assays as average number of spots in triplicate cultures. ${ }^{*}$ denotes $p<0.05$ using an unpaired Student $t$ test (control vs BTV). 
and to inactivated BTV-1 in 4 out of 5 mice. In sheep experimentally infected with BTV-8, we detected proliferative responses and IFN- $\gamma$ production not only to BEIinactivated BTV-8 but also to BTV-4. However no proliferative response or specific IFN- $\gamma$ production to BTV-1 was detected (Figures $1 \mathrm{C}$ and $1 \mathrm{D}$ ). It remains unclear whether this difference in response is due to a different antigen repertoire presented to the host, or to a mechanism of immune evasion specific to BTV-1. Taken together, these results confirm that $\mathrm{T}$ cells from infected animals can cross-react with several serotypes.

\section{Prediction of peptide binding from NS1 protein to $\mathrm{H}-2^{\mathrm{b}}$ haplotype and binding assays}

Using a combination of three epitope prediction algorithms available on the web (SYFPEITHI, Pro-Pred-I, NetMHC I and II) [22-25], 11 peptides from NS1 protein from BTV-8 were selected and synthesised (Table 1). The ability of these synthesised peptides to bind $\mathrm{H}-2 \mathrm{D}^{\mathrm{b}}$ and $\mathrm{K}^{\mathrm{b}}$ molecules was assessed using a binding assay on RMA-S cells. All 8 peptides predicted to bind murine MHC class I molecules showed binding affinity for either $\mathrm{D}^{\mathrm{b}}$ or $\mathrm{K}^{\mathrm{b}}$ molecules. NS1 peptide binding was ranked according to the binding to RMA-S cells of the control peptide gp33-41. Four NS1 peptides displayed a strong affinity for either $\mathrm{D}^{\mathrm{b}}$ or $\mathrm{K}^{\mathrm{b}}$ molecules, and conversely, 3 NS1 peptides only had low affinity for their MHC molecules (Table 1). Peptide NS1(222) displayed, as predicted, moderate binding to both $\mathrm{D}^{\mathrm{b}}$ and $\mathrm{K}^{\mathrm{b}}$ molecules. Overall, the NetMHC algorithm appears to predict more accurately the peptide binding to $\mathrm{D}^{\mathrm{b}}$ and $\mathrm{K}^{\mathrm{b}}$ molecules, although NS1(403) peptide which was not predicted to bind using this algorithm had weak affinity for $\mathrm{D}^{\mathrm{b}}$ in RMA-S cell binding assays. Thus, we can conclude that the combination of several predictive algorithms proved useful for the detection of putative $\mathrm{T}$ cell epitopes.

\section{Response to $D^{b}$ and $K^{b}$ binding NS1 peptides}

Splenocytes from BTV-8 inoculated mice were cultured for $48 \mathrm{~h}$ in the presence of NS1 peptides and the specific IFN- $\gamma$ production was assessed using ELISPOT assays (Figure 2A). Only peptide NS1(125) showed a significant IFN- $\gamma$ production in 5 out of 6 mice tested, which was significant using a Mann Whitney rank test comparing the NS1(125) peptide group to the control group. Peptides NS1(141), NS1(152), NS1(166) I, NS1(222), NS1 (235) and NS1(403) showed significant IFN- $\gamma$ production in 3 or 4 mice out of 6 (by student $t$ test), whereas peptide NS1(14) induced specific IFN- $\gamma$ production in only 1 mouse out of 6 and thereby was not investigated further. We then proceeded to generate CTL lines specific for these NS1 peptides from splenocytes of inoculated mice. After 5-6 days of in vitro stimulation with NS1 peptide, splenocyte cultures were tested for cytotoxicity by ${ }^{51}$ chromium release assay against RMA-S cells either pulsed with the NS1 peptide of interest or gp33-41 peptide as control (Figure 2B). Peptides NS1(125), NS1 (152), NS1(235) and NS1(403) generated CTLs in BTV8 inoculated mice, whereas no evidence of specific CTL activity was detected to NS1(141), NS1(166) I, or NS1 (222) peptides. Taken together, these data suggest that NS1(125), NS1(152), NS1(235) and NS1(403) peptide are CTL epitopes from NS1 in the context of $\mathrm{H}-2^{\mathrm{b}}$.

To analyse whether these 4 peptides were naturally processed and presented by target cells cultured with BTV (Figure 2C). MC57 cells were incubated with BEIBTV either from serotype 1,4 or 8 and used as target cell for CTL raised against NS1(125), NS1(152), NS1 (235) or NS1(403) peptide. MC57 cells were pulsed with the relevant NS1 peptide as positive control, or with mock BHK lysate as negative control. CTLs specific for NS1(152), NS1(235) or NS1(403) peptide were able to lyse target cells cultured with BTV-8. However, CTLs specific for NS1(125) peptide failed to recognise target cells cultured in the presence of BTV. Importantly, CTLs specific for NS1(152) or NS1(403) peptide were capable of lysing target cells pulsed either with BTV-1 or BTV-4, demonstrating that these CTLs can recognise cells infected with different BTV serotypes. Therefore, NS1(152) and NS1(403) peptides are naturally processed by other BTV serotypes and are capable of inducing cross-reactive CTL responses.

\section{Response to $\mathrm{I}-\mathrm{A}^{\mathrm{b}}$ binding peptides}

Production of IFN- $\gamma$ to putative I-A ${ }^{\mathrm{b}}$ binding peptides from NS1 was measured by ELISPOT assays on splenocytes from BTV-8 inoculated mice (Figure 3A). No peptide displayed consistent production of IFN- $\gamma$ in these assays, but peptides NS1(166) II and NS1(522) showed significant cytokine production (by Student's $t$ test) in 3 out of 6 mice tested. Proliferation was measured using ${ }^{3} \mathrm{H}$-thymidine incorporation in lymph node cells (Figure 3B) and splenocytes (Figure 3C) from BTV-8 inoculated C57BL/6 mice cultured for $72 \mathrm{~h}$ in the presence of NS1 peptides. Peptide NS1(166) II showed significant proliferative response in splenocytes (Mann Whitney test) whereas peptides NS1(402) and NS1(522) did not displayed significant and consistent proliferative responses in spleen (Figure 3C). In lymph nodes, peptides NS1(166) II and NS1(522) showed significant proliferative response (Figure 3B). Moreover, intracellular staining for IFN- $\gamma$ and TNF- $\alpha$ demonstrated by flow cytometry that CD4+ T cells responded to NS1(166) II and NS1 (522) peptides, but not to NS1(402) peptide (Figure 3D). Taken together, these data indicated that NS1(166) II and NS1(522) peptides are CD4 epitopes from BTV-8 in $\mathrm{C} 57 \mathrm{BL} / 6$ mice. 


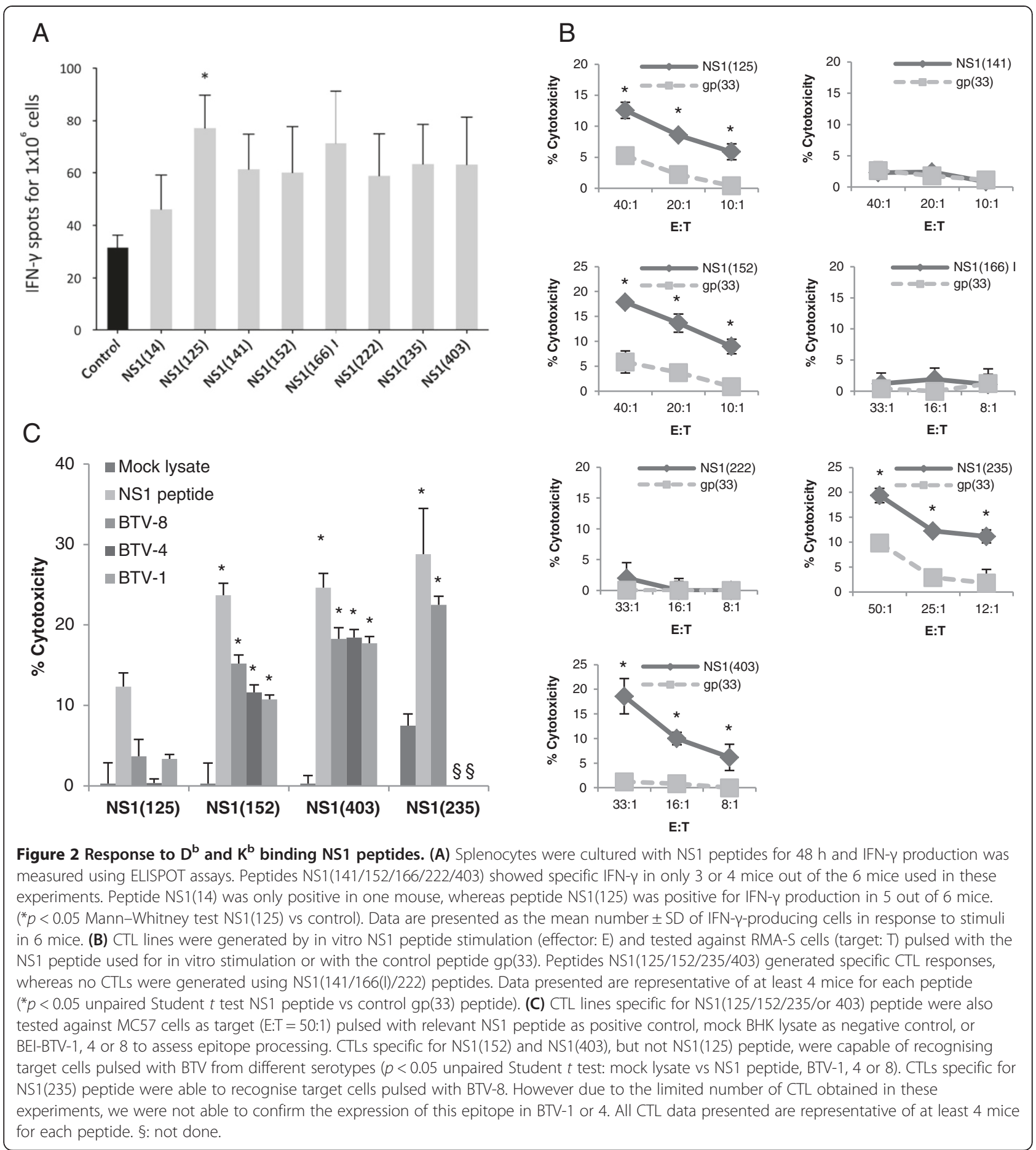

\section{Response to predicted NS1 peptides in sheep}

To determine whether some degree of overlap in these epitopes is present in BTV-8-infected sheep, we stimulated in vitro PBL from sheep infected experimentally with BTV-8 with NS1 peptides. After 48 h, the specific IFN- $\gamma$ response was assessed using an ELISPOT assay (Figure 4). Peptides NS1(141) and NS1(522) showed significant IFN- $\gamma$ production in most infected sheep.
Peptide NS1(166) II was also immunogenic but to a lesser extent (in 5 out of 8 sheep tested). Therefore, we further investigate peptides NS1(141) and NS1(522). PBL from infected sheep were cultured in the presence of NS1 peptide, and proliferation was assessed using ${ }^{3} \mathrm{H}$ thymidine incorporation at day 5 (Figures $5 \mathrm{~A}$ and $5 \mathrm{~B}$ ). Peptide NS1(141) and NS1(522) induced proliferative response in 3 out of 4 tested sheep. These data confirmed 


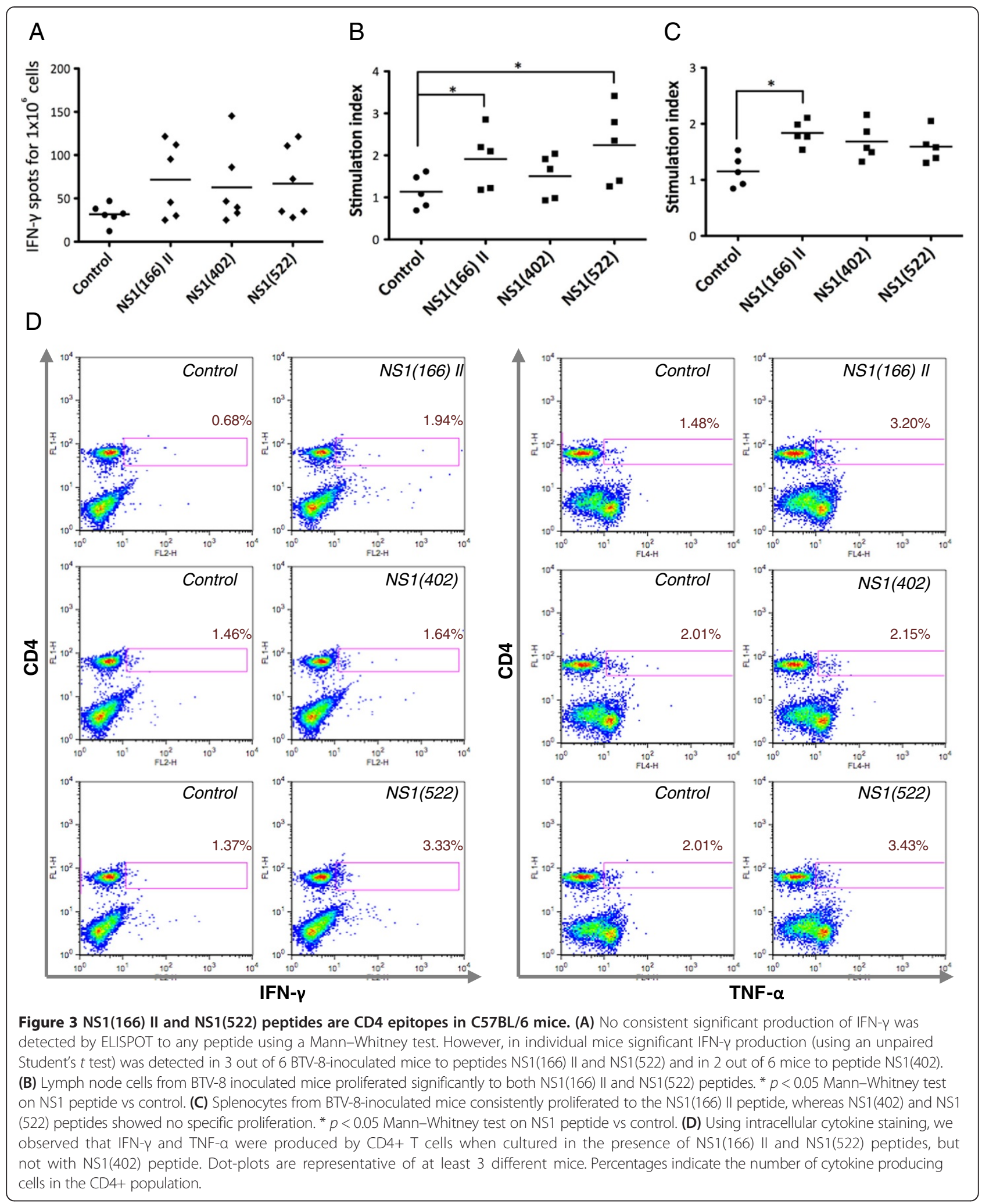




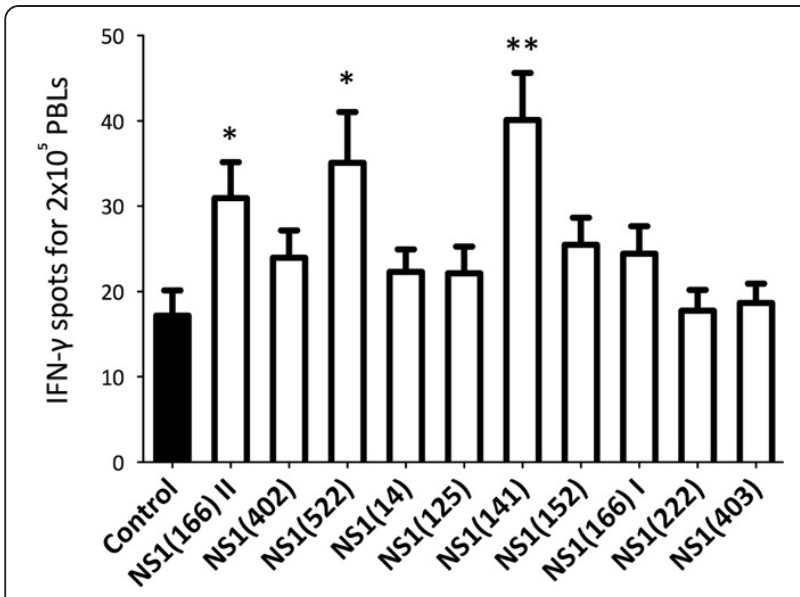

Figure 4 Sheep PBL responses to NS1 predicted peptides. PBLS from sheep infected experimentally with BTV-8 were cultured for $48 \mathrm{~h}$ with NS1 peptides and specific IFN- $\gamma$ response was measured using an ELISPOT assay. Peptide NS1(141) and NS1(522) showed specific IFN- $\gamma$ production in 7 out of 8 sheep. Peptide NS1(166) II showed specific IFN- $\gamma$ production in 5 out of 8 sheep. Data are presented as the mean number \pm SD of IFN- $\gamma$-producing cells in response to stimuli in 8 sheep. ${ }^{*} p<0.05$ and ${ }^{* *} p<0.01$ Mann Whitney test NS1 peptide group vs control.

that NS1(141) and NS1(522) peptides are immunogenic in sheep. To determine whether NS1(141) and NS1(522) peptides elicit $\mathrm{CD}^{+}$or $\mathrm{CD}^{+} \mathrm{T}$ cell responses, sheep PBL were stimulated with peptide and intracellular IFN$\gamma$ was measured by flow cytometry (Figure $5 \mathrm{C}$ ). For both peptides, IFN- $\gamma$ was detected in $\mathrm{CD} 4^{+} \mathrm{T}$ cells but not in $\mathrm{CD}^{+} \mathrm{T}$ cells. Thus, these data indicate that NS1(141) and NS1(522) peptides are CD4 epitopes in sheep.

To establish whether these $\mathrm{CD}^{+} \mathrm{T}$ cells specific for NS1(141) or NS1(522) peptide can cross-react with several BTV serotypes, sheep PBL stimulated with these peptides were cultured in the presence of BEI-BTV from different serotypes (Figure 6). In some cases, BEI-BTV stimulation resulted in IFN- $\gamma$ production in the CD4 negative compartment to all 3 serotype tested, probably as a result of antigen recognition by BTV-specific CD8 $+\mathrm{T}$ cells still present in the PBL cultures. This suggests that CD8 epitopes can also be shared among serotypes in sheep. Cells specific for both peptides were capable of producing IFN- $\gamma$ not only to the serotype used for inoculation (BTV-8) but also to BTV-1 and BTV-4. Therefore, these data indicate that NS1(141) and NS1(522) are CD4 epitopes shared among several BTV serotypes.

\section{Discussion}

In the present work, we described CTL and T helper epitopes from the NS1 protein of BTV-8 in mice and sheep. Three CTL and 2 helper epitopes were described in C57BL/6 mice, and 2 helper epitopes were described in sheep. These $\mathrm{T}$ cells are naturally activated during BTV-8 infection and are likely to contribute to the elimination of the virus. As previously described [18], we confirmed that $\mathrm{T}$ cells can cross-react with other BTV serotypes. Interestingly, IFN- $\gamma$ production to BTV-1 was always lower when compared to BTV-8 or BTV-4, indicating either that this strain can interfere with IFN- $\gamma$ production or that BTV-1 may not share some antigenic determinants responsible for the IFN- $\gamma$ production observed with its other two serotypes. It remains unclear whether the different response to BTV-1 observed in these experiments was due to a different antigen repertoire presented to the host, or to a mechanism of immune evasion specific to BTV-1.

Murine models for BTV infection are well established [19,27] and represent a very useful tool to design more rational and cost-effective vaccination strategies for the disease. The description of $\mathrm{T}$ cells determinants in mice will therefore allow for a better monitoring of effective vaccination to the virus in these experimental models. In turn, this is likely to further improve the design of novel vaccination approaches in the natural host. Predictive algorithms for MHC binding peptides have proved useful in identifying $\mathrm{T}$ cell epitopes for virus or tumour antigens [28]. In the present work, we have used a combination of algorithms available on the web to predict $\mathrm{H}-2^{\mathrm{b}}$ binding peptides from NS1. The binding to MHC class I molecules of these predicted peptides was verified using binding assay with RMA-S cells [21,29]. The NetMHC algorithm appears to predict more accurately the binding to $\mathrm{D}^{\mathrm{b}}$ and $\mathrm{K}^{\mathrm{b}}$ molecules than the other 2 algorithms. However, NS1(403) peptide which was a predicted binder using SYFPEITHI and ProPred-I algorithms but not by the NetMHC algorithm showed weak affinity for $\mathrm{D}^{\mathrm{b}}$ in RMA-S cell binding assays. Importantly, in spite of its weak binding NS1 (403) peptide was a CTL epitope shared among several BTV serotypes. On the other hand, NS1(125) peptide which showed strong binding to $\mathrm{D}^{\mathrm{b}}$ could elicit IFN- $\gamma$ production but displayed only a weak CTL activity in inoculated mice, with no evidence of natural processing in BTV-infected cells. Taken together these data confirm that MHC binding affinity alone is not always a good predictor of CTL activity, and that immune responses may be directed to low affinity peptides [30].

The immunogenicity of these predicted peptides was assessed in BTV-8 inoculated mice using a combination of IFN- $\gamma$ ELISPOT assays, intracellular cytokine staining, CTL assays (for MHC class I binding peptides) and proliferation assays (for MHC class II binding peptides). Only NS1(125) peptide displayed consistent IFN- $\gamma$ production in all inoculated mice. However, this peptide only displayed weak CTL activity and no evidence of natural processing was 


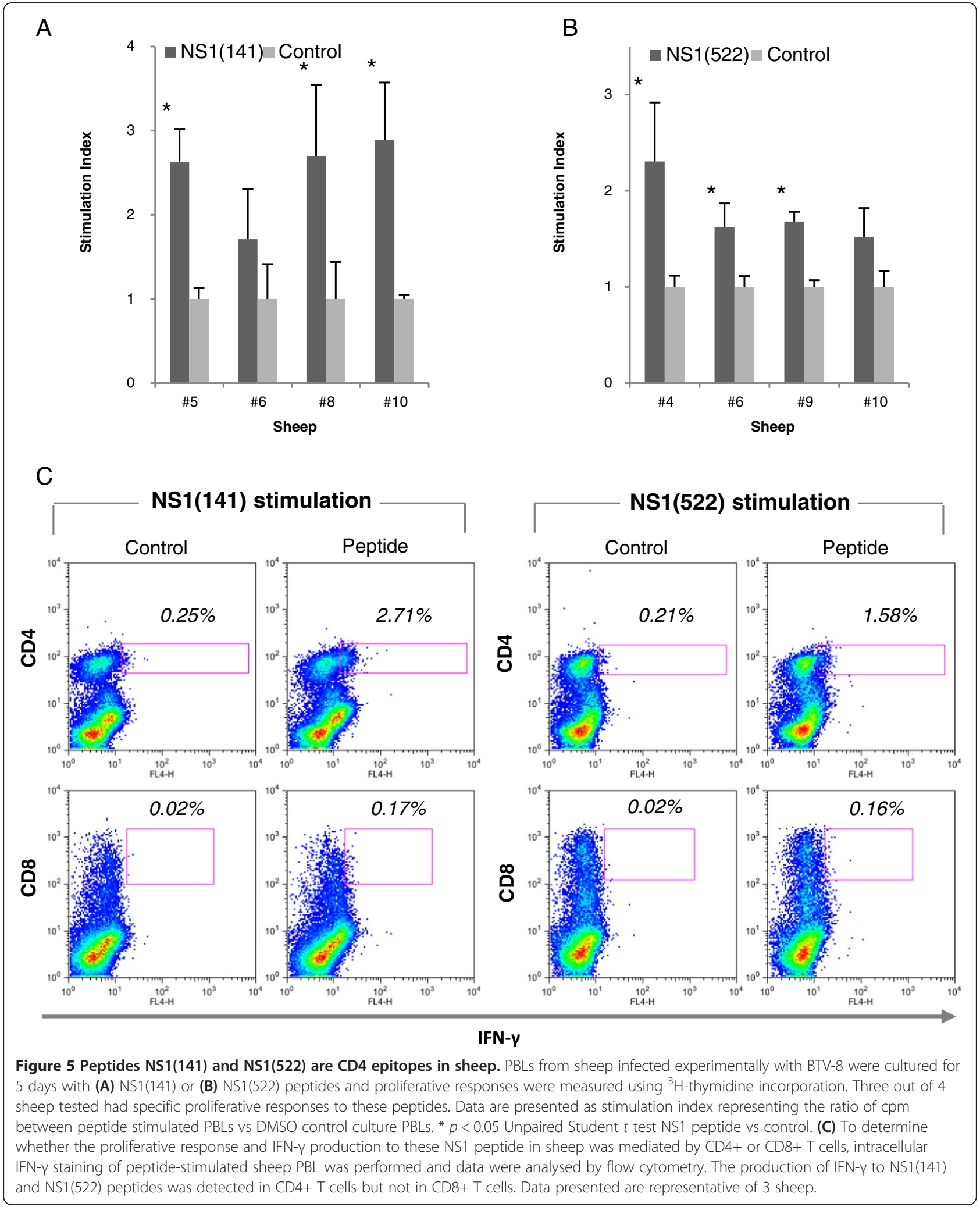




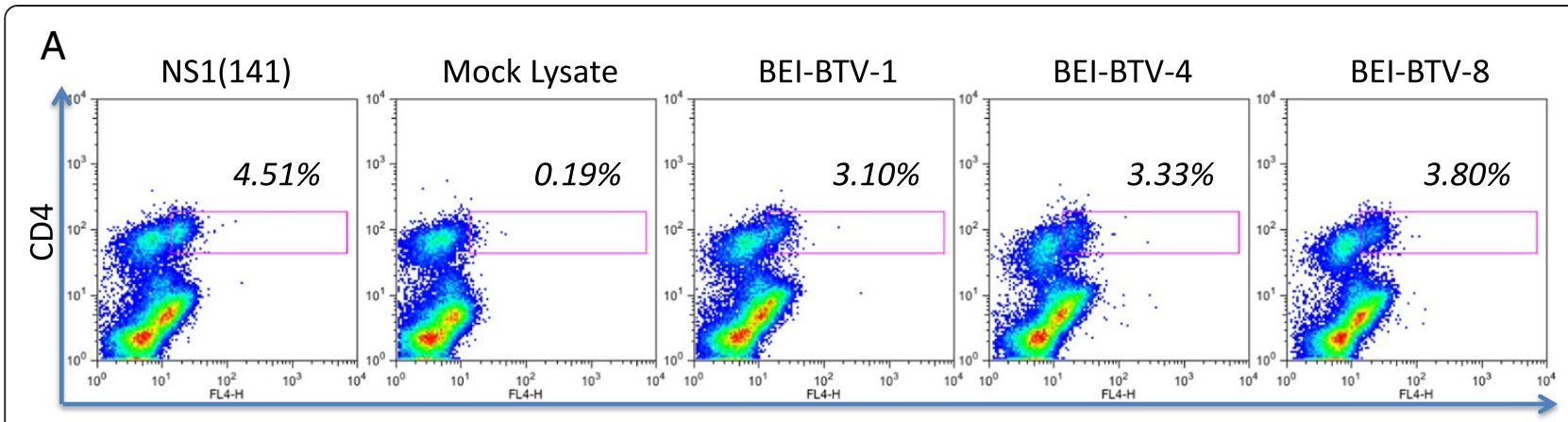

IFN- $\gamma$

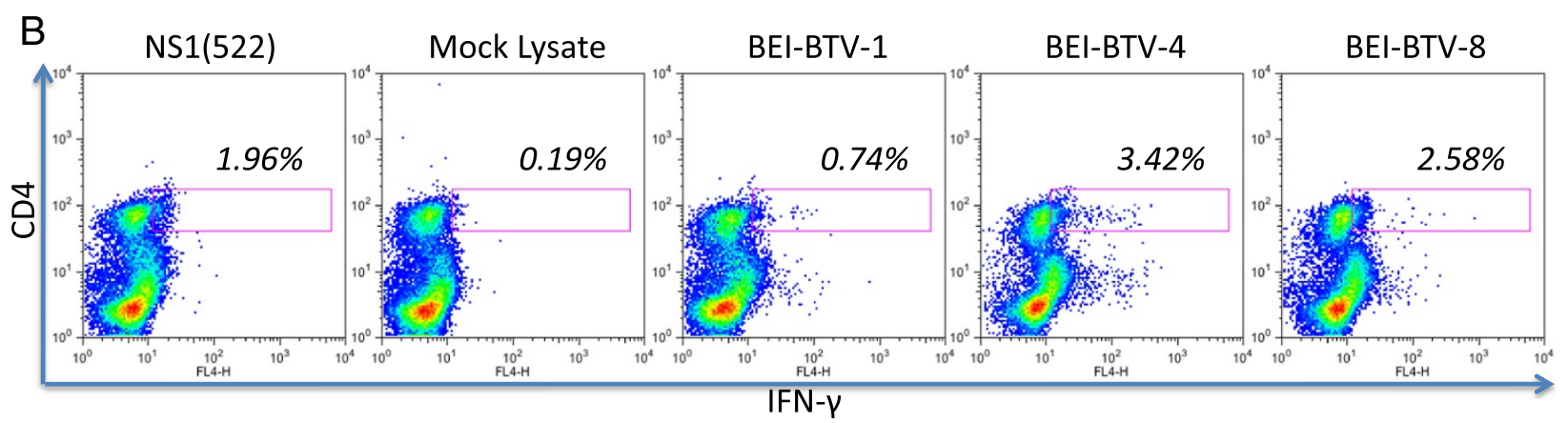

Figure 6 Peptide NS1(141) and NS1(522) are presented by several BTV serotypes. PBLs from infected sheep were stimulated either with (A) NS1(141) or (B) NS1(522) peptide. After 1-week expansion, IFN- $\gamma$ production was assessed against several BTV serotypes. CD4+ T cells specific for NS1(141) or NS1(522) were able to produce IFN- $\gamma$ not only in the presence of BTV-8 (used for infection) but also for BTV-1 and -4 .

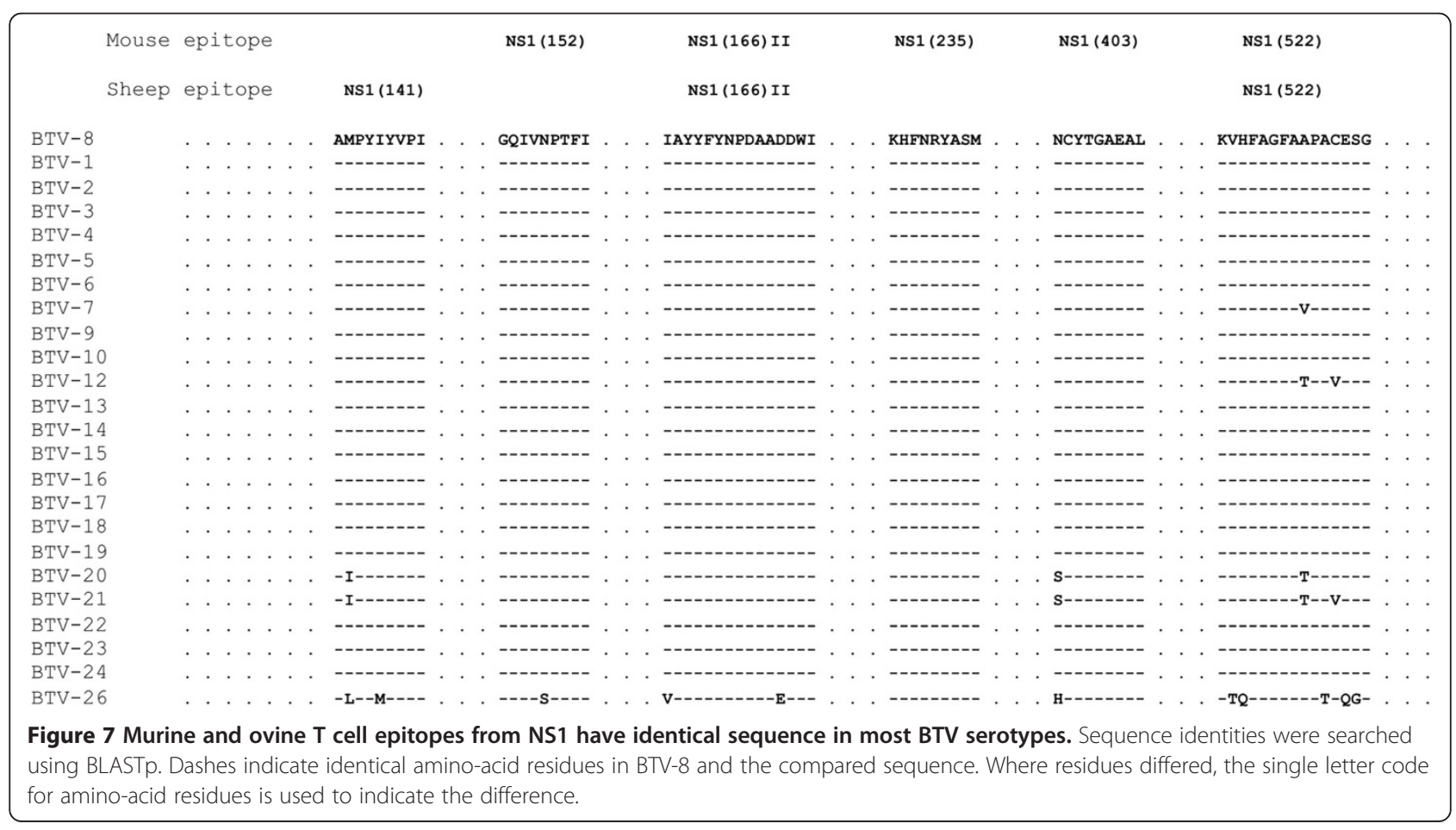


observed in cell pulsed with BTV. Peptides NS1(152), NS1(235) and NS1(403) induced moderate IFN- $\gamma$ production, however they displayed consistent CTL activity and were able to lyse target cells pulsed with BTV. Two CD4 epitopes were also identified in C57BL/6 inoculated mice using a combination of proliferation assay and intracellular cytokine staining. These data highlight the importance of using several complementary techniques to identify novel epitopes.

Importantly, we were able to show that peptides NS1(152) and NS1(403) could recognised cells pulsed with different BTV serotypes demonstrating that these CTL epitopes are presented by other viral serotypes. In the case of CTL raised against NS1(235) peptide, we were not able to use target cells pulsed with other BTV serotypes due to the limited amount of cells obtained in these experiments. Nonetheless, it is very likely that NS1(235) will also be presented by other BTV serotypes as its sequence is identical in BTV-1 and BTV-4. Moreover, the sequences from these NS1 epitopes are shared among a wide variety of BTV serotypes (Figure 7). Thereby, vaccination activating $\mathrm{T}$ cells responses to these epitopes is likely to set the basis for a better protection across BTV serotypes.

We also describe two CD4 epitopes from NS1 in sheep. Both of these helper epitopes were not only presented by BTV-8, but also by BTV-1 and BTV-4. Definition of these cross-reactive epitopes is an essential part of the ongoing effort to improve BTV vaccination and monitoring. From a biological point of view, defining these $\mathrm{T}$ cell epitopes will help understand the process of infection of BTV, as well as its interaction with the host immune system. The susceptibility that BTV displays to type I interferon as well as the lymphopenia observed in the host after infection, indicate that BTV is immunosuppressive [31]. Animals that recover from the infection develop a strong humoral and cellular immunity to the virus, demonstrating that effective immunity to BTV can be eventually mounted. However during the infection period, animals are immune-compromised and therefore susceptible to opportunistic infections. A better understanding of the T cell response to BTV may be central to comprehend the mechanisms through which this virus is capable of evading the host immune response and often persist for month in the host [32].

The characterisation of more $\mathrm{T}$ cell determinants from BTV in breeds used widely in sheep farming is also important for the monitoring of the health status of naive populations to BTV. In addition, this knowledge may help understand the susceptibility of these breeds to BTV outbreaks. Vaccination designed to activate $\mathrm{T}$ cells specific for determinants shared among serotypes is also likely to limit the economical impact that BTV outbreaks can have on naïve populations.

\section{Competing interests}

The authors declare that they have not competing interests.

\section{Authors' contributions}

$J M R$, carried out most of the experiments described in the manuscript and wrote the article; LP participated in the animal handling; VM, carried out some of the experiments; NS, conceived the study and contributed in its design and coordination. All authors read and approved the final manuscript.

\section{Acknowledgements}

This work was funded by grants AGL2009-07353, RyC-2010-06516 and AGL2011-25025 from Ministerio de Economía y Competitividad (Spain) and 228394-NADIR Integrating Activities 7th EU program.

\section{Author details}

${ }^{1}$ Centro de Investigación en Sanidad Animal (CISA-INIA), Instituto Nacional de Investigación Agraria y Alimentaria, Valdeolmos, Madrid, Spain. ${ }^{2}$ Present address: Centro Nacional de Biotecnología, CSIC, Campus de Cantoblanco, Madrid, Spain.

Received: 9 October 2013 Accepted: 27 February 2014

Published: 12 March 2014

\section{References}

1. Schwartz-Cornil I, Mertens PP, Contreras V, Hemati B, Pascale F, Breard E, Mellor PS, MacLachlan NJ, Zientara S: Bluetongue virus: virology, pathogenesis and immunity. Vet Res 2008, 39:46.

2. Roy P: Bluetongue virus proteins and particles and their role in virus entry, assembly, and release. Adv Virus Res 2005, 64:69-123.

3. Ratinier M, Caporale M, Golder M, Franzoni G, Allan K, Nunes SF, Armezzani A, Bayoumy A, Rixon F, Shaw A, Palmarini M: Identification and characterization of a novel non-structural protein of bluetongue virus. PLoS Pathog 2011, 7:e1002477.

4. Grimes JM, Burroughs JN, Gouet P, Diprose JM, Malby R, Zientara S, Mertens PP, Stuart DI: The atomic structure of the bluetongue virus core. Nature 1998, 395:470-478.

5. Mertens PP, Burroughs JN, Anderson J: Purification and properties of virus particles, infectious subviral particles, and cores of bluetongue virus serotypes 1 and 4. Virology 1987, 157:375-386.

6. Mertens PP, Crook NE, Rubinstein R, Pedley S, Payne CC: Cytoplasmic polyhedrosis virus classification by electropherotype; validation by serological analyses and agarose gel electrophoresis. J Gen Virol 1989, 70:173-185

7. Hassan SS, Roy P: Expression and functional characterization of bluetongue virus VP2 protein: role in cell entry. J Virol 1999, 73:9832-9842

8. Huismans H, Van Dijk AA: Bluetongue virus structural components. Curr Top Microbiol Immunol 1990, 162:21-41.

9. Han Z, Harty RN: The NS3 protein of bluetongue virus exhibits viroporin-like properties. J Biol Chem 2004, 279:43092-43097.

10. Jeggo MH, Wardley RC, Taylor WP: Role of neutralising antibody in passive immunity to bluetongue infection. Res Vet Sci 1984, 36:81-86.

11. Andrew M, Whiteley P, Janardhana V, Lobato Z, Gould A, Coupar B: Antigen specificity of the ovine cytotoxic T lymphocyte response to bluetongue virus. Vet Immunol Immunopathol 1995, 47:311-322.

12. Jeggo MH, Wardley RC, Brownlie J: Importance of ovine cytotoxic T cells in protection against bluetongue virus infection. Prog Clin Biol Res 1985, 178:477-487.

13. Jeggo MH, Wardley RC, Brownlie J: A study of the role of cell-mediated immunity in bluetongue virus infection in sheep, using cellular adoptive transfer techniques. Immunology 1984, 52:403-410.

14. Stott $J L$, Barber TL, Osburn BI: Immunologic response of sheep to inactivated and virulent bluetongue virus. Am J Vet Res 1985, 46:1043-1049.

15. Stott JL, Osburn Bl, Barber TL: The current status of research on an experimental inactivated bluetongue virus vaccine. Proc Annu Meet US Anim Health Assoc 1979, 83:55-62. 
16. Takamatsu H, Jeggo MH: Cultivation of bluetongue virus-specific ovine $\mathrm{T}$ cells and their cross-reactivity with different serotype viruses. Immunology 1989, 66:258-263.

17. Janardhana V, Andrew ME, Lobato ZI, Coupar BE: The ovine cytotoxic T lymphocyte responses to bluetongue virus. Res Vet Sci 1999, 67:213-221.

18. Umeshappa CS, Singh KP, Pandey AB, Singh RP, Nanjundappa RH: Cellmediated immune response and cross-protective efficacy of binary ethylenimine-inactivated bluetongue virus serotype-1 vaccine in sheep. Vaccine 2010, 28:2522-2531.

19. Calvo-Pinilla E, Rodriguez-Calvo T, Sevilla N, Ortego J: Heterologous prime boost vaccination with DNA and recombinant modified vaccinia virus Ankara protects IFNAR(-/-) mice against lethal bluetongue infection. Vaccine 2009, 28:437-445.

20. Jabbar TK, Calvo-Pinilla E, Mateos F, Gubbins S, Bin-Tarif A, BachanekBankowska K, Alpar O, Ortego J, Takamatsu HH, Mertens PP, Castillo-Olivares $\mathrm{J}$ : Protection of IFNAR (-/-) mice against bluetongue virus serotype 8 , by heterologous (DNA/rMVA) and homologous (rMVA/rMVA) vaccination, expressing outer-capsid protein VP2. PloS One 2013, 8:e60574.

21. Rojas JM, Rodriguez-Calvo T, Pena L, Sevilla N: T cell responses to bluetongue virus are directed against multiple and identical CD4+ and CD8+ T cell epitopes from the VP7 core protein in mouse and sheep. Vaccine 2011, 29:6848-6857.

22. Rammensee H, Bachmann J, Emmerich NP, Bachor OA, Stevanovic S: SYFPEITHI: database for MHC ligands and peptide motifs. Immunogenetics 1999, 50:213-219.

23. Singh H, Raghava GP: ProPred1: prediction of promiscuous MHC Class-I binding sites. Bioinformatics 2003, 19:1009-1014.

24. Nielsen M, Lundegaard C, Worning P, Lauemoller SL, Lamberth K, Buus S, Brunak S, Lund O: Reliable prediction of T-cell epitopes using neural networks with novel sequence representations. Protein Sci 2003, 12:1007-1017

25. Nielsen M, Lund O: NN-align. An artificial neural network-based alignment algorithm for MHC class II peptide binding prediction. BMC Bioinformatics 2009, 10:296.

26. Sevilla N, Kunz S, Holz A, Lewicki H, Homann D, Yamada H, Campbell KP, de La Torre JC, Oldstone MB: Immunosuppression and resultant viral persistence by specific viral targeting of dendritic cells. J Exp Med 2000, 192:1249-1260.

27. Calvo-Pinilla E, Rodriguez-Calvo T, Anguita J, Sevilla N, Ortego J: Establishment of a bluetongue virus infection model in mice that are deficient in the alpha/beta interferon receptor. PloS One 2009, 4:e5171.

28. Rojas JM, McArdle SE, Horton RB, Bell M, Mian S, Li G, Ali SA, Rees RC: Peptide immunisation of HLA-DR-transgenic mice permits the identification of a novel HLA-DRbeta1*0101- and HLA-DRbeta $1{ }^{* 0401-r e s t r i c t e d ~ e p i t o p e ~}$ from p53. Cancer Immunol Immunother 2005, 54:243-253.

29. Andersen ML, Ruhwald M, Nissen MH, Buus S, Claesson MH: Self-peptides with intermediate capacity to bind and stabilize MHC class I molecules may be immunogenic. Scand J Immunol 2003, 57:21-27.

30. Jorgensen KW, Rasmussen M, Buus S, Nielsen M: NetMHCstab - predicting stability of peptide:MHC-I complexes; impacts for CTL epitope discovery. Immunology 2014, 141:18-26.

31. Umeshappa CS, Singh KP, Nanjundappa RH, Pandey AB: Apoptosis and immuno-suppression in sheep infected with bluetongue virus serotype-23. Vet Microbiol 2010, 144:310-318.

32. Takamatsu H, Mellor PS, Mertens PP, Kirkham PA, Burroughs JN, Parkhouse RM: A possible overwintering mechanism for bluetongue virus in the absence of the insect vector. J Gen Virol 2003, 84:227-235.

doi:10.1186/1297-9716-45-30

Cite this article as: Rojas et al:: Ovine and murine T cell epitopes from the non-structural protein 1 (NS1) of bluetongue virus serotype 8 (BTV-8) are shared among viral serotypes. Veterinary Research 2014 45:30.

\section{Submit your next manuscript to BioMed Central and take full advantage of:}

- Convenient online submission

- Thorough peer review

- No space constraints or color figure charges

- Immediate publication on acceptance

- Inclusion in PubMed, CAS, Scopus and Google Scholar

- Research which is freely available for redistribution
C Biomed Central 